rev.relac.int.estrateg.segur.5(1):51-82,2010

\title{
IMPERIOS Y COLONIALISMO, 1870-1914 ¿UNA ERA DE GLOBALIZACIÓN, GEOPOLÍTICA O NACIONALISMO ECONÓMICO?
}

\author{
Oscar Granados Erazo*
}

No deseo que un único pueblo sea al tiempo dominador y proveedor del universo

Cicerón

\section{RESUMEN}

La era de 1870 a 1914 se convirtió en un periodo donde los países del Centro podían contar con la posibilidad de avanzar rápidamente bajo un esquema económico serio y soportado sobre la gestión gubernamental y la responsabilidad de sus dirigentes. Pero fue la misma vanidad política e imprecisión diplomática la que condujo a que la competencia económica, los avances económicos y la acumulación de capital en diferentes lugares del sistema económico internacional se desvanecieran y se convirtieran en la piedra angular para sustentar los asuntos políticos, el poder, la rivalidad territorial, la hegemonía imperial y, finalmente, la financiación de la Gran Guerra. Sería el inicio de un periodo donde las diferencias en

\footnotetext{
* Economista, Universidad Externado de Colombia. Magister en Relaciones Internacionales, Pontificia Universidad Javeriana. Magister en Asuntos Internacionales, Universidad Externado de Colombia. Director Maestría en Relaciones y Negocios Internacionales, Universidad Militar Nueva Granada. Co-Director Grupo de Investigación de Estudios Internacionales y Políticos, Universidad Militar Nueva Granada. oscar.mge@gmail.com
} 
el desarrollo económico se ampliarían y se afectaría la estabilidad futura del sistema político y económico internacional.

Palabras clave: Imperialismo, globalización, nacionalismo económico, inversión extranjera, poder.

\begin{abstract}
The era from 1870 to 1914 became a period in which the Central countries could have the possibility to move forward swiftly under a sober economic scheme, sustained on government achievement and the responsibility of their leaders. But, it was political vanity itself and diplomatic imprecisions which caused that economic competition, economic progress and capital buildup in various sectors of the international economic system, faded away to become the cornerstone that supported the political affairs, the power, the territorial rivalry, the imperial dominance and finally the financing of the Great War. It would be the beginning of a period in which the differences in economic development would grow and affect the future stability of the international political and economic systems.
\end{abstract}

Key words: Imperialism, globalization, economic nationalism, foreign investment, power

\title{
INTRODUCCIÓN
}

...el equilibrio rara vez surge de un designio consciente.

Kissinger

La historia mundial se ha estructurado sobre el avance, consolidación y decadencia de los imperios en diversas y diferentes dimensiones. Desde la historia antigua, y en los lugares más apartados de nuestro planeta, han existido los imperios, con estructuras perdurables en el tiempo, como el Imperio Romano; con una importante capacidad militar, pero con debilidades de gestión, como el Imperio Mongol; o con capacidad impositiva, pero con serias limitantes económicas, como el Imperio Español. «Una extraordinaria variabilidad en la cronología, así como en la extensión geográfica de sus dominios» ${ }^{1}$. Así mismo, se pasa de imperios intensivos en coerción a imperios intensivos en capital, que facilitan aún más su proceso de fortalecimiento no sólo como imperios, sino como naciones.

El siguiente análisis se enfoca en un periodo donde el interés nacional, la carrera hegemónica y la importancia del aparato económico se convirtieron en la piedra angular de las decisiones y la

${ }^{1}$ Ferguson (2006) p.48

IMPERIOS Y COLONIALISMO, 1870-1914 ¿UNA ERA DE GLOBALIZACIÓN, GEOPOLÍTICA O NACIONALISMO ECONÓMICO? 
estrategia diplomática de los países entre 1870 y 1914 . Al pasar de la rivalidad territorial a la competencia económica se tiene como consecuencia un incremento en el promedio anual del comercio mundial de mercancías: para el periodo comprendido entre 1876 y 1880 era de 6.010 millones de dólares en exportaciones y 7.060 millones de dólares en importaciones; entre 1911 y 1913 pasaría a ser de más de 18.320 millones de dólares en exportaciones y 19.920 millones de dólares en importaciones de promedio anual².

Es importante determinar si ese avance imperialista y la reactivación del colonialismo se soporta sobre la tesis de la geopolítica, el nacionalismo económico o de la globalización, estableciéndose como la primera era de la globalización; o más bien una evolución imperial que se determina por la multipolaridad, rivalidad y la falta de un imperio hegemónico, fundamentada sobre la raison d'état de los franceses, la realpolitik de los alemanes o simplemente el interés nacional, el cual se soportaría sobre la estrategia internacional de los países que deseaban iniciar una carrera hegemónica, la cual había sido diezmada durante más de cincuenta años por la capacidad y estrategia del imperio británico. Así mismo, el avance del transporte y las comunicaciones, que dependiendo de la dinámica económica de cada Estado y la consolidación de sus recursos financieros, lograban fortalecer aún más su capacidad de conquista y colonización.

Aunque el análisis no solamente se debe sustentar en el aspecto político, que habitualmente enmarca las características del imperialismo, también debe precisar que los elementos económicos lanzaron a los países en esta carrera, apoyados posiblemente sobre la vanidad política de Guillermo II, la intención de gloria "pour la gloire» de una Francia necesitada de renovar herencias y de unos Estados Unidos listos a mostrar sus credenciales constitucionales en el terreno internacional, con una base económica amplia y suficiente para lograrlo.

Pero realmente ¿cuál es el límite del avance imperial? Se podría determinar que era el factor económico, la capacidad militar, el conocimiento geográfico o el afán de hegemonía; o como menciona Henry Kissinger en su obra: «iHasta dónde se podía llegar antes de que los intereses del Estado se consideraran satisfechos? ¿Cuántas guerras se necesitaban para alcanzar la seguridad?»3. ¿Qué se necesitaba para mantener a flote un modelo económico que estaba perdiendo su capacidad, su productividad, y donde posiblemente los rendimientos decrecientes del capital cada vez eran más frecuentes para economías maduras como la británica?; o para países como Estados Unidos y Alemania, que estaban empezando a consolidarse gracias a su fortaleza y dinámica económica, la cual se soportaba sobre la innovación, los rendimientos crecientes del capital y los procesos migratorios para, el caso de Estados Unidos.

Es importante determinar si el equilibrio europeo durante parte importante del siglo XIX se logró por el interés político, el equilibrio de poder, la deficiencia económica o los procesos de alianza. El

\footnotetext{
2 Yates (1959) p.28

${ }^{3}$ Kissinger (1995) p. 61
} 
juego de las alianzas permite contrarrestar el avance del país que desea imponer su hegemonía y así mantener el equilibrio de poder; de lo contario, se logra la dominación y se rompe el orden internacional. Esta premisa permitió que Europa estuviera en un supuesto equilibrio durante más de cuarenta años. Aunque con la Guerra de Crimea, en el decenio de 1850, a pesar de que para muchos historiadores estos fueron eventos de poca trascendencia, se inició un desequilibrio en Europa que no finalizaría hasta la culminación de la Segunda Guerra Mundial, con varios periodos en donde la paz fue un estado de odio, resentimiento y revanchismo que culminaría en el siguiente enfrentamiento.

La necesidad de mantener el equilibrio condujo a generar varias situaciones que iban desde alianzas hasta guerras, dejando de lado cualquier parámetro histórico; lo importante era salvaguardar su posición dentro del sistema internacional. De esta manera se desarrollaron situaciones de trascendencia como la consolidación de la Independencia de los Estados Unidos y su posterior Guerra de Secesión, entre 1861 y 1865; la Guerra de Unificación Italiana, en 1859, o la misma Guerra Pruso-Danesa, en 1864; la Guerra Austro Prusiana, en 1866, o la Guerra Franco Prusiana, en 1870. ¿Eran situaciones netamente políticas?

Posiblemente las potencias de Europa querían emular un Dios en la tierra, como lo plantea Hobbes, pero nunca pensaron que esa estrategia estaba siendo analizada por varios Estados para obtener parte de los beneficios que había logrado hasta ese momento Inglaterra. Pero, irealmente los beneficios que se querían emular se lograban con actividades coloniales? o era algo más sencillo y propio de la condición humana, como buscar los beneficios que habían gozado históricamente diferentes territorios, y más precisamente en el último siglo los británicos, porque no hay nada más molesto para el bienestar y el buen juicio de una persona que ver a un amigo hacerse rico ${ }^{4}$, y en el caso de las potencias europeas, las cuales estaban sumidas en una historia de enfrentamientos y rivalidades, ¿sería esta una razón adicional para fortalecer esa competencia?

Varios autores, con diferentes vertientes teóricas, han analizado el periodo de 1870 y 1914 como un punto relevante en el avance general del sistema internacional, encontrando diversas razones que sustentan la intención imperial, como los trabajos de Hobson y Lenin; las características de la primera era de globalización, en especial por Niall Ferguson; una situación de evolución internacional de auge y decadencia de las potencias, en cabeza de Kennedy y del mismo Ferguson; desde una perspectiva de ciclos y evolución económica, como Lewis, Arrighi, Wallerstein y Braudel; de ineficiencia económica, como Luxemburgo; desde la economía política, como Gilpin, Keohane, entre otros; o de evolución política internacional, como Kissinger. Sin embargo, aquí no se tendría el espacio para vincular una infinidad de trabajos que, desde diferentes ópticas de las ciencias sociales, han enmarcado esta Era, como un periodo vital en la evolución y el cambio histórico del mundo.

De esta forma se plantea que los imperios se consolidaron durante la era de 1870 a 1914, a partir de la competencia económica, y que su nueva rivalidad territorial se desprendió de la vanidad

\footnotetext{
${ }^{4}$ Kindleberger (1989) p. 36 
política y hegemónica a partir de una jerarquización de las relaciones internacionales, para la cual era importante contar con una capacidad económica y una gestión gubernamental adecuada.

A continuación se revisan los aspectos más relevantes de la política internacional de 1870 a 1914, el avance imperial de las potencias del momento, los resultados individuales y colectivos que se lograron en ese proceso y, finalmente, los sucesos que llevarían a la confrontación armada de la Primera Guerra Mundial. El documento se divide en cuatro secciones: una primera en donde se revisan desde una perspectiva de la teoría política y la economía política internacional algunos elementos que nos permiten identificar las características de este periodo; en una segunda sección se revisa las características de un nuevo imperialismo, si parten de una estrategia económica o política; en una tercera sección se presenta cómo se estructura ese afán hegemónico que conduciría a la culminación de un periodo de interacción económica internacional de dimensiones globales, transformándose en la gran guerra; y, finalmente, una sección de conclusiones.

\section{DE LA TEORÍA POLÍTICA A LA ECONOMÍA POLÍTICA DE LOS IMPERIOS Y EL COLONIALISMO}

La paz es el efecto natural del comercio

Montesquieu

¿Cómo lograr determinar un enfoque teórico, con una gran cantidad de hechos que se reunieron en un periodo de tiempo, que vislumbraba la culminación de una época que se había caracterizado por la imposición y la gestión de los británicos y su muy conocida Pax Britannica? Para esto se utilizan tres enfoques que pueden determinar la cercanía del liberalismo con la globalización, el nacionalismo con la geopolítica y el mismo nacionalismo económico, y el marxismo con una estructura que identifica la necesidad que tiene el capitalismo de expandirse para lograr mantener unos beneficios constantes fortaleciendo su capacidad de acumulación y de esta forma influir y hasta determinar la política exterior de los países.

Establecerlo desde el punto de vista económico no necesariamente deja de lado aspectos que son vitales para entender la razón de las invasiones, los protectorados, las imposiciones económicas o simplemente la consolidación de negocios comerciales o financieros, que se desarrollaron durante este periodo. Esto como resultado de la percepción de las grandes potencias sobre los demás países del contexto internacional, pues su accionar claramente muestra formas diferentes de establecer relaciones entre y con los Estados.

Se parte de la importancia de la soberanía, a la cual es confiada la salud del Estado ${ }^{5}$, y puesto que la relación de los Estados tiene como base su respectiva soberanía, su legitimidad, especialmente

\footnotetext{
${ }^{5}$ Hegel (1975) p. 277
} 
en tanto está orientado al exterior, la del poder de su soberano, constituye, por un lado, una relación que se refiere completamente a lo interno, ningún Estado debe inmiscuirse por la fuerza en la constitución y el gobierno de otro Estado 6 ; y por otro lado, debe ser cumplida a la par, esencialmente por el reconocimiento de los demás Estados. Ese reconocimiento exige una garantía, esto es, que él acepte igualmente a los otros, que deben reconocerlo, es decir, que han de respetarlo en su independencia; por lo tanto, no puede serle indiferente a lo que suceda en su interior. Por ejemplo, en un pueblo nómada, que se encuentre en un bajo nivel de cultura, se presenta la cuestión de saber hasta qué limite puede ser considerado como Estado ${ }^{7}$.

Esta es una explicación de por qué los países que contaban con la capacidad económica, política y militar podrían, bajo su escala de valoración, establecer las relaciones con los diferentes Estados y, aún mas, reconocer su importancia como Estado o no; y a partir de ahí definir su estrategia económica y política hacia ese territorio. ¿Cuál era la diferencia entre el territorio ghanés y el territorio brasilero? ¿Por qué mientras en Brasil se hacían negociaciones importantes de financiación de proyectos de infraestructura o de comercio con el Imperio Británico y sus diferentes empresarios y banqueros, en Ghana se buscaba desplazar a los holandeses y hacerse cargo del territorio para establecerlo como una colonia inglesa?

Se podría establecer que la diferencia de continente y el mismo Congreso de Berlín, son los que dan un tratamiento diferente a Ghana y Brasil, pero para sustentar este mismo argumento, lo podemos hacer con territorios en el mismo continente: Guyana y Brasil o la misma Argentina. ¿Por qué se avanzaba en la consolidación de negocios e inversiones con Brasil y Argentina, siendo de los destinos más importantes del portafolio de inversiones del Imperio Británico, y por qué manejar una acción impositiva y sanguinaria contra la población de Guyana, después de la salida abrupta de los holandeses en $1796 ?^{8}$ Una salida que no es nada diferente a la que sufrieron los españoles y, en cierta forma, los portugueses, dos décadas después, en territorios posiblemente más importantes y estratégicos que el territorio guyanés.

De esta forma, la tesis de Hegel se aplica al accionar de las grandes potencias, donde dependiendo de las características del Estado se consideraba o no como tal y su estrategia sería diferente, pasando por encima la importancia que para esa época ya tenían los Estados en el contexto internacional y su elemento vital: la soberanía. Es decir, que bajo la primera era de globalización, las potencias se encontraban lejos de dejar atrás la herencia y percepción de los Estados que habían manejado durante siglos, donde simplemente eran territorios que contaban con recursos importantes para sus intereses y que en cualquier momento podrían ser objeto de una guerra o conquista, olvidando los intereses de los pueblos, las características propias de las sociedades conquistadas y lógicamente

\footnotetext{
${ }^{6}$ Kant (2001) p. 106

7 Ibid. (1975) p. 327

${ }^{8}$ Aunque algunos ingleses trataron de aprovechar la situación de España a principios del siglo XIX con intentos de invasión similares a algunos lugares en América del Sur como Buenos Aires, Riohacha, entre otros.
} 
el consentimiento y los derechos de la población de estos territorios. El agresor que se pone en un estado de guerra con otro e injustamente invade sus derechos no puede jamás, como resultado de esa guerra injusta, tener derecho alguno sobre el conquistado, esto es algo en lo que estará de acuerdo todo hombre que no piense que los ladrones y piratas tienen derecho a mandar sobre aquellos a quienes han dominado por la fuerza; y tampoco podrá estar nadie obligado a cumplir promesas que le han sido arrancadas ilegalmente mediante intimidación y violencia ${ }^{9}$.

Aunque las potencias no aceptaran las características de muchos territorios como Estados, y no tuvieron, según ellos, las posibilidades de constituirse como tal, no les daría el derecho de iniciar una conquista contra ese territorio y mucho menos de establecer los recursos y riquezas como propios, algo que permitió el avance económico, el sustento para el fortalecimiento político y, a su vez, la seguridad, la defensa de sus territorios y el dominio por la fuerza de sus colonias o territorios conquistados. El poder que un conquistador obtiene sobre aquellos a los que ha vencido en una guerra justa (la imposición y conquista no son elementos de una guerra justa) es perfectamente despótico. Implica tener el poder absoluto sobre las vidas de aquellos que, al ponerse a sí mismos en un estado de guerra, han perdido la garantía de conservarlas; mas no tendrá el conquistador derecho alguno a tomar sus posesiones ${ }^{10}$.

En los Estados despóticos la naturaleza del gobierno obliga a una obediencia extrema; una vez conocida la voluntad del príncipe, debe esta surtir efecto tan infaliblemente como produce el suyo una bola que golpea a la otra. No da lugar para atenuaciones, modificaciones, acomodos, plazos, equivalencias, tratos o reconvenciones, ni proponer algo igual o mejor ${ }^{11}$; algo que era soportado por la población y los territorios que eran afectados por los procesos de conquista, sin revisar hasta qué punto esa característica de despotismo se estuviera desarrollando al interior de los Estados que estaban iniciando una competencia en el sistema internacional.

Eran nuevamente unidades absolutas sin subordinación ni dependencia alguna, al menos en lo concerniente a las principales de ellas, y esas unidades se afirman o en todo caso se buscan, procuran afirmarse en un espacio que ha pasado a ser el de la competencia y la dominación comerciales, un espacio de circulación monetaria, un espacio de conquista colonial, un espacio de control de los mares, todo lo cual da a la afirmación de cada Estado por sí mismo no solo la forma de autofinalidad, sino la nueva forma de la competencia ${ }^{12}$; algo que era vigente para este nuevo escenario de competencia que, como lo explica Foucault, se gesta en la lucha de las ciudadesEstado italianas y posteriormente en la consolidación y el avance de imperios durante los años siguientes a la caída del imperio romano y la fragmentación del poder de la Iglesia con el Tratado

\footnotetext{
${ }^{9}$ Locke (1690) p. 178

${ }^{10}$ Ibíd. p. 182

${ }^{11}$ Montesquieu (1748) p. 32, Libro III, 10

${ }^{12}$ Foucault (2004) p. 335
} 
de Westfalia. Las relaciones entre Estados dejaron de percibirse en la forma de la rivalidad para concebirse en la dimensión de la competencia a partir de los siglos XV y XVI ${ }^{13}$.

A partir de estos elementos, que se pueden definir como una única tesis, se desarrollan algunas características de cada uno de los enfoques de economía política mencionados anteriormente, para determinar cuál se establece como el esquema más acertado para explicar una era donde los países vivieron su mayor transformación.

Bajo el esquema liberal, el Estado se convierte en un pequeño agente que interactúa en algunas actividades, pero es el mercado y el mecanismo de precios el que determina la dinámica de la estructura económica de los países. Sin embargo, claramente los Estados interactuaron de forma decidida y en compañía de los empresarios y banqueros para iniciar su actividad colonial, imperial e impositiva en los diferentes lugares en donde sus capacidades se lo permitieran. Es decir, la acumulación de capital de cada uno de los países fue el que determinó la capacidad militar, la capacidad naval y la posibilidad de interactuar económicamente a partir de excedentes de producción que fueran determinantes o importantes para los mercados internacionales y su comercio, conduciéndolos a establecer que la persecución de los objetivos diferentes de la eficiencia, necesariamente involucrará un costo en términos de pérdida de eficiencia ${ }^{14}$, y eso será el causante en rezagarse en la competencia económica entre naciones, algo que en esta época cada vez era más visible y que posteriormente se convertiría en una competencia militar. Algo diferente a lo sucedido anteriormente; en esta Era la dinámica económica de los países se soportaba en la movilidad de los factores de producción, en el intercambio de bienes y servicios y en importantes procesos de innovación que iban de la mano para lograr mejorar procesos productivos que permitieran reemplazar productos extranjeros e ingresar en mercados diferentes al propio.

Aunque los liberales no ven ninguna conexión necesaria entre el proceso de crecimiento económico y acontecimientos políticos tales como la guerra y el imperialismo, estos males políticos afectan y pueden ser afectados por las actividades económicas, pero están determinados esencialmente por factores políticos y no económicos (...) Para ellos la economía es progresiva y la política regresiva, por lo cual consideran que el progreso está divorciado de la política y basado en la evolución del mercado $^{15}$, o en palabras de Kindleberger, donde establece que una posible diferencia entre la política y la economía, es que el cambio económico es mucho más continuo, y el cambio político es mucho más discontinuo. Esto es lo suficientemente obvio cuando los gobiernos son alterados bajo las condiciones constitucionales ${ }^{16}$. Y sustentado en la capacidad del mercado de regular y organizar las relaciones económicas de oferta y demanda, no existiría necesidad de iniciar acciones

\footnotetext{
${ }^{13}$ Ibid. p. 337

${ }^{14}$ Gilpin (1987) p. 56

${ }^{15}$ Ibid. p. 43

${ }^{16}$ Kindleberger (1970) p. 13
} 
impositivas contra territorios que pueden equilibrar los desajustes que tengan los diferentes mercados, sino simplemente el mercado entregaría a los mercados internacionales la responsabilidad de equilibrar los excesos y faltantes de factores de producción, bienes y servicios, así como la estabilidad de los precios.

Este último punto se logró como parte de la institucionalización de los mercados de materias primas y los mercados financieros, que permitían contrarrestar el diferencial de precios. Sin embargo, este no es un mecanismo independiente y único para lograr la movilidad de los factores de producción y el equilibrio de las economías. Aunque bajo el esquema de intercambio comercial, se podría sustentar la importancia de los mercados en su facilidad para lograr la estabilización económica; es claro que el intercambio pocas veces es libre y equitativo ${ }^{17}$, y mucho menos en una época donde algunas actividades estaban concentradas en los hombres de negocios de las potencias, en importantes terratenientes de países en Latinoamérica o en los empresarios locales sujetos a las imposiciones y restricciones de los banqueros y transportadores extranjeros.

Estos elementos podrían determinar que el imperialismo y el colonialismo se sustentaban sobre factores geopolíticos y por una intención de mantener las bondades de la rivalidad territorial como las directrices de la consolidación del poder, la seguridad y la soberanía nacional. Y los avances económicos y del comercio internacional se sustentaban sobre un proceso de globalización de los factores de producción: capital, trabajo y el intercambio de bienes y servicios; es decir, eran procesos independientes. La movilidad de los bienes básicos, el capital y el trabajo lograron niveles récord, las líneas marítimas y el telégrafo a través del Atlántico nunca habían estado más ocupados, el capital y los migrantes viajaban hacia el oeste y las materias primas y las manufacturas viajaban hacia el este. En relación con la producción, la exportación tanto de mercancías como de capitales no se volvería a ver sino hasta los años $1980^{18}$.

El enfoque nacionalista, que se consolida desde los inicios mercantilistas, muestra la importancia de la vinculación de la economía y el Estado para sustentar el poder y salvaguardar la riqueza, apoyando el proceso geopolítico. Esta relación ve en el mercado mundial la posibilidad de fortalecer aún más la capacidad económica que su mercado interno no le permite y lograr avanzar en el poder; aunque nunca menciona las debilidades de su economía como la razón para acceder a los mercados externos. Prácticamente todos los mercantilistas, fuera cual fuera su época, país o estatus individual, podrían haber suscrito la totalidad de las proposiciones siguientes: 1) La riqueza es un recurso absolutamente esencial para el poder, sea con fines de seguridad o defensa; 2) el poder es esencial o de gran valor como medio para adquirir o retener la riqueza; 3) la riqueza y el poder son, cada uno por sí mismo, adecuados fines últimos de la política nacional; 4) a largo plazo, hay armonía entre estos fines, aunque en circunstancias particulares puede ser necesario hacer sacrificios económicos durante un cierto tiempo, a favor de la seguridad militar y, en consecuencia, también

\footnotetext{
${ }^{17}$ Lindblom (1977) p.40

${ }^{18}$ Ferguson (2005) p.64
} 
de la prosperidad a largo plazo ${ }^{19}$; esto nos acerca a que el nacionalismo económico se basa en la doctrina realista de las relaciones internacionales ${ }^{20}$.

Desde esta perspectiva, los intereses pueden sobrepasar cualquier esquema soberano o elemento de la libertad individual, con el objetivo de consolidar el poder y la riqueza que lo sustenta; es por esto que el avance de Europa y su consolidación económica a partir del colonialismo permitió obtener factores de producción con que no contaba y necesitaba para mantener su proceso de rivalidad; de esta forma, los bienes básicos y la mano de obra esclava de las colonias hizo posible el capitalismo europeo, y el capital europeo no tenía ningún interés en renunciar a estos ${ }^{21}$.

Utilizando el enfoque marxista es relevante verificar algunos aspectos que sustentan la base y la relación de su teoría económica para ser conectada con la situación imperial y colonial de la época. Durante el siglo XIX, Gran Bretaña, después de fortalecer su capacidad interna, empleó su poder para promover y mantener una economía mundial abierta. Utilizaron su influencia para que se levantara toda barrera al libre flujo de bienes y capitales, y ese mayor poder de las naciones desarrolladas impuso a los socios renuentes las posibilidades del comercio internacional y la división del trabajo ${ }^{22}$. En ese proceso de fortalecer su capacidad y sus intereses económicos, fueron los gestores de los lineamientos del libre mercado, pero Inglaterra, siendo ese gran líder del liberalismo, empieza a encontrar trastornos en su equilibrio económico por el avance de otros países que contaban con un mejor proceso de innovación y progreso tecnológico, el cual afianzaba su dinámica económica y la productividad de sus factores de producción. Debido a esto, inició una retirada de sus conceptos liberales y buscó la forma de proteger su economía. El sistema liberal comenzó a retraerse lentamente ${ }^{23}$ e Inglaterra dejó de ser la potencia económica única del siglo XIX, y compartiría su lugar en diversas industrias con Estados Unidos y Alemania; en otros sectores cedería esa capacidad, debido a la inflexibilidad de su economía en respuesta al ascenso de nuevas potencias industriales ${ }^{24}$.

Mientras que los marxistas creen que el Estado es, en último término, el sirviente de la clase económica dominante, los realistas ven al Estado como una entidad relativamente autónoma, la cual persigue intereses que no pueden reducirse a los intereses particulares de ninguna clase. Para los marxistas, el sistema internacional y la política exterior están determinados por la estructura de la economía nacional, para los realistas, la naturaleza del sistema internacional es el determinante fundamental de la política exterior (...) Los marxistas consideran a la guerra, el imperialismo y el

\footnotetext{
${ }^{19}$ Viner (1958) p. 286

${ }^{20}$ Gilpin (1987) p. 55

${ }^{21}$ Hardt y Negri (2000) p.115

22 Kuznets (1966) p. 335

${ }^{23}$ Gilpin (1987) p. 65

${ }^{24}$ Lewis (1978) p. 133
} 
Estado como manifestaciones perversas del capitalismo, que desaparecerán con la revolución comunista (dictadura del proletariado); los realistas sostienen que son rasgos ineludibles de un sistema político internacional anárquico ${ }^{25}$.

El marxismo establece el colapso del capitalismo por su propio avance, esto significa que el mercado interno no tiene la capacidad de optimizar el uso de los factores de producción, de esta manera, no absorbe en su totalidad la oferta y no cuenta con los medios para producir todos los bienes y servicios que demanda. Por esta razón acude al sistema económico internacional, el cual le permite equilibrar su economía y el avance de la misma.

El proceso de acumulación de capital es parte fundamental para el avance de las economías, pero esa acumulación convive con los rendimientos decrecientes o, lo que es lo mismo, con la caída de las tasas de beneficio. Este elemento fundamenta la necesidad de acudir al sistema internacional y se vinculará a él generando relaciones de intercambio de dependencia e impositivas.

Las relaciones de intercambio se dieron con los países del centro, es decir, los países industrializados que contaban con una infraestructura política suficiente para estar al mismo nivel. Las relaciones de dependencia estuvieron vinculadas con países semi-industrializados que empezaban a florecer como naciones, gracias a la consolidación de procesos de independencia, pero aún dominados por clases sociales muy fuertes y minoritarias, como los terratenientes, y en ocasiones con el apoyo de la Iglesia. En un tercer grupo se estructuraron las relaciones impositivas, que fueron aquellas que llevaron a las potencias a apoderarse de infinidad de territorios y regiones que no contaban con una suficiencia económica, una estabilidad política o, mejor, una ineficiencia en la gestión de los gobiernos que ayudaron para que las potencias avanzaran sobre ellas.

Es así como la vinculación entre la teoría política y nuestra teoría económico- política sustenta que el avance de las potencias durante este periodo se presentó debido a la necesidad de equilibrar su economía, explicado por la teoría marxista, acudiendo a los elementos que hacían de los Estados y su soberanía una estructura jerárquica, por las características de su sistema político y económico, y la posibilidad de cambiar su esquema de relación: intercambio, dependencia o imposición. Aclarando que no todos los procesos económicos en mercados internacionales se sustentaran exclusivamente en acciones coloniales, sino en relaciones jerarquizadas. Explicar a profundidad la jerarquización que hacían cada una de las potencias sobre los diversos territorios y naciones del mundo en ese momento, se sale del objetivo de este documento.

Dado que las economías capitalistas crecen y acumulan capital en proporciones diferentes, un sistema capitalista internacional no puede ser estable sino por muy breves periodos de tiempo, de acuerdo con los preceptos marxistas, lo que conduciría al colapso del capitalismo. Pero el colapso del capitalismo, aunque podría posponerse durante siglos, a través del mecanismo del comercio

${ }^{25}$ Gilpin (1987) p. 55 
ultramarino y de la inversión extranjera ${ }^{26}$, es factible que se sustente más como la necesidad de un ajuste a partir de desequilibrios políticos, como son las guerras, que claramente se logran sostener con los recursos económicos y, por ende, por la base productiva e industrial de cada país.

\section{EL NUEVO IMPERIALISMO: ¿ESTRATEGIA ECONÓMICA O POLÍTICA?}

El mundo está casi completamente parcelado y lo que queda de él está siendo dividido, conquistado y colonizado. Pienso en esas estrellas que uno ve en lo alto a la noche, esos vastos mundos que nunca podamos alcanzar. Anexaría los planetas si pudiera; a menudo pienso en eso. Me pone triste verlos tan claros y sin embargo tan lejos.

Cecil Rhodes

Después de un acomodamiento territorial al interior de Europa con la unificación de Prusia y los territorios alemanes, así como de Italia y los ajustes generados por las guerras Austro-Prusiana y Franco-Prusiana, se inició el surgimiento del espíritu colonial, que para algunos era algo nuevo en los territorios de ultramar, pero para otros era una posible restructuración territorial y el camino para fortalecerse al interior de Europa, siguiendo el ejemplo del Imperio Británico, que durante décadas se había consolidado como potencia gracias a su interacción comercial y colonialismo con los territorios de ultramar, y sin dejar de lado la historia del Imperio español y portugués, que se habían beneficiado tanto de su política imperial del siglo XVI y XVII.

Aunque claramente, algunos países en Europa no participan en el nuevo proceso imperial, que se iniciaba con la Conferencia de Berlín de 1885 -con la vinculación no solamente de las estructuras gubernamentales sino también de empresarios, comerciantes y banqueros-, sí tendrían la capacidad para avanzar en el sistema internacional. En estos aspectos la Conferencia de Berlín sobre África Occidental puede considerarse, simbólicamente, como el cenit del periodo de predominio de la vieja Europa en los asuntos mundiales ${ }^{27}$. Lo cual se logró mantener gracias a la herencia colonial de España, Portugal, Bélgica y Holanda y los mismos avances de Rusia, pues en esta nueva etapa no tenían la capacidad de avanzar sobre este territorio. Era la forma de defender y mantener los reductos de una hegemonía imperial del pasado. Y en ocasiones involucrarse en competencias que no podrían sostener, debido a que las responsabilidades imperiales van agrandando paso a paso un gobierno indeciso ${ }^{28}$.

Se inicia entonces una rivalidad, más allá de la verificación de la importancia geoestratégica, por tener cualquier espacio que contuviera el avance de la otra potencia; un proceso agresivo en búsqueda de grandeza con altas implicaciones económicas. El imperialismo agresivo no solo impide

\footnotetext{
${ }^{26}$ Ibid. p. 75

${ }^{27}$ Kennedy (1987) p. 315

${ }^{28}$ Koebner (1949) p. 8
} 
el avance hacia el internacionalismo al fomentar la enemistad de los imperios rivales, sino que, con su ataque contra las libertades y contra la propia existencia de las razas más débiles o inferiores, provoca en estas un exceso correlativo de autoconciencia nacional ${ }^{29}$.

La real-politik, creada en Alemania como una forma de hacer política, remodeló todo el arte de la diplomacia e hizo del objetivo de la expansión y el engrandecimiento nacionales sin piedad ni escrúpulos la fuerza motriz que deliberadamente iba a condicionar toda la política exterior ${ }^{30}$. Algo que buscó emular de los imperios del pasado o vigentes en ese momento, donde la grandeza no se dio por la estabilidad económica exclusivamente sino por la transferencia cultural y política: la simple vanidad de los gobernantes de mostrar su grandeza, así las finanzas de su reino estuvieran en déficit. Por esto, conceptos como Hinterland fueron la creación de una visión global de las estructuras territoriales y su vinculación a cualquier precio, en esferas de interés o esferas de influencia.

Aunque algunas variables de los países del centro no estaban dirigidas exclusivamente hacia una estrategia política, sino que la misma pérdida de oportunidades era cada vez más frecuente en Inglaterra, se generó una exportación de factores de producción a los mercados internacionales, no por una intención de ampliación del imperio, sino por una deficiencia económica con la que ya contaba: bajo el nivel de oportunidades laborales y rendimientos decrecientes del capital. Cuanto mayor y más dinámico fuera el mercado doméstico de un Estado respecto a los restantes Estados, mejores oportunidades tendría ese Estado de expulsar al Reino Unido de la posición central que ocupaba en las redes globales de las relaciones patrón-cliente que constituían el mercado mundial ${ }^{31}$, y ese fue el caso de países como Alemania y Estados Unidos.

Esta es la razón para que muchos territorios fueran partícipes de una globalización y un libre mercado, sin tener un importante avance como naciones con estructuras económicas internacionales, sino más bien con mercados internos incipientes, como vehículos de la expansión económica de los países industrializados que ya empezaban a mostrar debilidades en su equilibrio macroeconómico. Es posible que esta sea una de las razones para que Fieldhouse mencione que la palabra imperialismo haya perdido su inocencia ${ }^{32}$, porque ya nos internábamos en un imperialismo que se sustentaba exclusivamente en los procesos económicos privados de acumulación de capital, y no en la tradicionalidad de los siglos anteriores para financiar con los recursos de las colonias una rivalidad al interior de Europa; pasábamos al imperialismo financiero o especulativo del Señor Rhodes ${ }^{33}$.

En palabras de Rosa Luxemburgo, el capitalismo es el primer modo de la economía que no puede existir por sí mismo, que necesita de otros sistemas económicos como medio y como terreno para

\footnotetext{
${ }^{29}$ Hobson (1902) p. 32

30 Ibid. p. 33

31 Arrighi (1999) p. 80

${ }^{32}$ Fieldhouse (1961) p. 188

${ }^{33}$ Koebner (1949) p. 16
} 
prosperar $^{34}$, posiblemente se acerque a ser una explicación contundente de la situación internacional de ese momento, donde los países necesitaron de los mercados internacionales para ajustar su situación, que se desprendía de los rendimientos decrecientes del capital y la debilidad en la creación de empleos. Los países que aún no se encontraban en tal situación aprovecharon esas transferencias de factores de producción de la nación hasta ese momento más desarrollada: mano de obra y capital británico favorecerían el avance de Estados Unidos, Canadá y algunos países con procesos industriales más lentos como Australia, Argentina y, en menor medida, Brasil. Así como la posibilidad de recibir inversión extranjera que aceleraba procesos de extracción y explotación de recursos naturales (Ver Tabla 2.1).

La inversión europea se convirtió en una importante herramienta para avanzar en la competencia económica, pero en ocasiones esa inversión extranjera se consolidó, sobre todo en el caso británico, como parte del impacto que sufría en la transformación industrial y en los rendimientos decrecientes del mercado interno, y no simplemente por un excedente de capital que se presentaba por un pleno empleo de los factores de producción en su economía. Mientras las inversiones domésticas podrían alcanzar un rendimiento de $4.52 \%$ durante el periodo de 1870 a 1913, las inversiones extranjeras podrían estar en promedio en $5.81 \%^{35}$.

\begin{tabular}{|c|c|c|}
\hline \multicolumn{3}{|c}{$\begin{array}{c}\text { Tabla 2.1 } \\
\text { Emigración y Exportación de Capital de Gran Bretaña, 1870-1894 } \\
\text { En promedios anuales }\end{array}$} \\
\hline Periodo & $\begin{array}{c}\text { Emigración } \\
\text { (Miles) }\end{array}$ & $\begin{array}{c}\text { Exportación de capital } \\
\text { (millones de libras) }\end{array}$ \\
\hline $1870 / 1874$ & 206 & 73 \\
\hline $1875 / 1879$ & 124 & 28 \\
\hline $1880 / 1884$ & 262 & 56 \\
\hline $1885 / 1889$ & 251 & 80 \\
\hline $1890 / 1894$ & 202 & 64 \\
\hline Fuente: Lewis, A. (1978), p.55 \\
\hline
\end{tabular}

Así mismo, las economías alemana, francesa y estadounidense, en varias oportunidades, no lograron absorber en su totalidad los recursos y sufrieron recesiones y desequilibrios económicos importantes, que les obligó a buscar nuevos mercados para solventar su desequilibrio económico, teniendo presente la importante acumulación de capital que se estaba generando y la necesidad de lograr mejores rendimientos para sí mismos, dejando muchas veces de lado los enfoques políticos de sus avances imperiales y centrándose en cómo utilizarlos para lograr la estabilidad de su economía.

El Imperio Británico durante gran parte del siglo XIX había logrado implantar su modelo, y en este momento la madurez de su economía le permitía financiar e invertir en el lugar del mundo que más

\footnotetext{
${ }^{34}$ Luxemburgo (1968) p.365

${ }^{35}$ Pollard (1985) p. 496
} 
se ajustara a sus intereses económicos (Ver Tabla 2.2). La inversión extranjera directa se situaba en un promedio anual entre 1870 y 1874 de 61 millones de libras esterlinas, con desaceleraciones importantes durante los periodos de 1875 a 1879 y 1894 a 1904. La inversión británica se reactivaría y para el periodo entre 1904 y 1909 tendría un promedio anual de 109.5 millones de libras esterlinas, y para el periodo 1910 a 1913 de 185 millones $^{36}$.

La inversión extranjera directa francesa pasaría de 12 mil millones de francos en 1870 a 28 mil millones de francos para el año 1900, y antes de la Primera Guerra Mundial se encontraba en volúmenes aproximados a los 45 mil millones de francos ${ }^{37}$. Aunque claramente el lento proceso de iniciación por parte de Francia en los mercados financieros mundiales se dio por el impacto de la indemnización a Prusia, después de la Guerra Franco Prusiana, que ascendió a más de cinco mil millones de francos, los cuales fueron cancelados entre el primero de junio de 1871 hasta el 5 de septiembre de $1873^{38}$.

\footnotetext{
${ }^{36}$ Feis (1930) p. 11

37 Ibid. p.47

${ }^{38}$ Kindleberger (1984) p.243
} 
Tabla 2.2Inversión Extranjera Británica por destino, 1914En millones de Libras Esterlinas

\begin{tabular}{|c|c|c|c|c|c|}
\hline & Territorio & Valor & & Territorio & Valor \\
\hline \multirow{10}{*}{$\begin{array}{l}\text { 은 } \\
\text { 을 } \\
\text { 드 }\end{array}$} & Canadá & 514,9 & \multirow{11}{*}{ 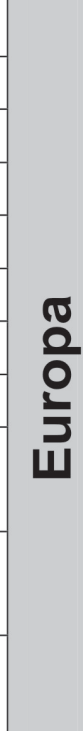 } & Rusia & 110,0 \\
\hline & Australia y Nueva Zelanda & 416,4 & & España & 19,0 \\
\hline & Suráfrica & 370,2 & & Italia & 12,5 \\
\hline & África Occidental & 37,3 & & Portugal & 8,1 \\
\hline & India y Ceilán (Sri Lanka) & 378,8 & & Francia & 8,0 \\
\hline & Estrechos Asiáticos & 27,3 & & Alemania & 6,4 \\
\hline & Borneo & 5,8 & & Austria & 8,0 \\
\hline & Hong Kong & 3,1 & & Dinamarca & 11,0 \\
\hline & Otras colonias & 26,2 & & $\begin{array}{l}\text { Estados } \\
\text { Balcánicos }\end{array}$ & 17,0 \\
\hline & Subtotal & $1.780,0$ & & Otros países & 18,6 \\
\hline \multirow{10}{*}{ 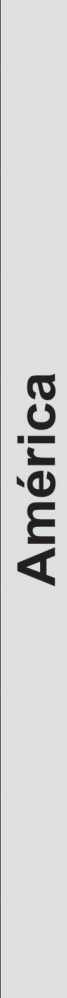 } & Estados Unidos & 54,6 & & Subtotal & 218,6 \\
\hline & Argentina & 19,6 & \multirow{6}{*}{$\begin{array}{l}00 \\
0 \\
0\end{array}$} & Egipto & 44,9 \\
\hline & Brasil & 48,0 & & Turquía & 24,0 \\
\hline & México & 9,0 & & China & 43,9 \\
\hline & Chile & 1,0 & & Japón & 62,8 \\
\hline & Uruguay & 36,1 & & Resto del Mundo & 77,9 \\
\hline & Perú & 34,2 & & Subtotal & 253,5 \\
\hline & Cuba & 33,2 & & & \\
\hline & Otros latinoamericanos & 25,5 & & & \\
\hline & Subtotal & $1.511,2$ & & Total & $3.763,3$ \\
\hline
\end{tabular}

Fuente: Feis (1930) p. 23 
El año de 1873 sería el inicio de un desequilibrio macroeconómico en Europa, que generaría unas de las crisis económicas más relevantes de finales de siglo, y se convertiría en un catalizador para iniciar los procesos de expansión colonial y la apertura de mercados extranjeros a cualquier precio, donde Francia sería uno de los grandes necesitados de solventar su situación. Sin embargo, Francia se convertiría en el tercer inversionista de Europa y ya para 1914 contaba con importantes destinos de inversión, no solo para soportar su dinámica económica sino también sus procesos de alianza, siendo Rusia su principal receptor de inversión y su mayor aliado en la carrera por el poder europeo (Ver Tabla 2.3).

Algo similar sucedía con Alemania, que después de su despegue como Nación y con los beneficios económicos de solventar una situación económica compleja durante el decenio de 1870, se involucraría como un exportador de capital de primer nivel, pero con una diferencia relevante y es que la inversión al interior de su territorio no se redujo, sino que fortalecieron aún más los procesos de innovación y progreso tecnológico, permitiendo avanzar en su capacidad industrial y económica; algo con lo que Inglaterra no contaba en la misma proporción. La inversión extranjera directa de Alemania pasó de 5 mil millones de Marcos en 1883 a duplicarse diez años después y a entrar en la fuerte competencia internacional con Gran Bretaña y avanzar a los 15 mil millones de Marcos en 1905 y llegar a un máximo de 23.5 mil millones de Marcos en 1914 ${ }^{39}$, con destinos tan diversos como los que había consolidado Inglaterra con un proceso más antiguo, sin descuidar ninguno de los lugares en donde sus competidores económicos estaban radicados o interesados en radicarse (Ver Tabla 2.4).

\begin{tabular}{|l|l|l|}
\hline \multicolumn{3}{|c|}{ Tabla 2.3 } \\
\multicolumn{2}{|c|}{$\begin{array}{l}\text { Inversión Extranjera Francesa x destino 1900 vs. } 1914 \\
\text { En miles de millones de Francos }\end{array}$} \\
\cline { 2 - 3 } Territorio & \multicolumn{2}{c|}{ Valor } \\
\hline \multicolumn{2}{|c|}{7,000} & 1914 \\
\hline Rusia & 2,0 & 3,3 \\
\hline Turquía (Asia y Europa) & 4,5 & 3,9 \\
\hline \multirow{2}{*}{ España y Portugal } & 2,5 & 2,2 \\
\hline Austria-Hungría & 0,7 & 2,5 \\
\hline Estados Balcánicos & & \\
\hline
\end{tabular}

${ }^{39}$ Feis (1930) p.71 


\begin{tabular}{|l|l|l|}
\hline Italia & 1,4 & 1,3 \\
\hline Suiza, Bélgica y Holanda & 1,0 & 1,5 \\
\hline Resto de Europa & 0,8 & 1,5 \\
\hline Colonias Francesas & 1,5 & 4,0 \\
\hline Egipto, Suez y Suráfrica & 3,0 & 3,3 \\
\hline Estados Unidos, Canadá y Australia & 0,8 & 2,0 \\
\hline Latinoamérica & 2,0 & 6,0 \\
\hline Asia & 0,8 & 2,2 \\
\hline Total & $\mathbf{2 8 , 0}$ & $\mathbf{4 5 , 0}$ \\
\hline Fuente: Feis 1930, p. $\mathbf{5 1}$ & & \\
\hline
\end{tabular}

Uno de los elementos que puede haber retrasado el ingreso a los mercados de capitales internacionales era su diversidad monetaria que se lograría reducir con dos elementos vitales en la conformación económica alemana: la unificación monetaria en 1871 y la creación del Reichsbank como Banco Central en 1875. Así como el apoyo de una red bancaria de primer nivel que cada vez más se involucraba en los mercados internacionales y se soportaba sobre patrimonios importantes y con una estrecha relación con el sector industrial ${ }^{40}$.

En 1914, los inversionistas extranjeros se concentraban en Inglaterra, Francia, Alemania, Estados Unidos y, en menor medida, en Holanda, Bélgica y Suiza; teniendo como destino principal la misma Europa con 27.3\%, América Latina con 19.3\%, Estados Unidos con 15.5\%, Asia con 13.6\%, África con $10.7 \%$, Canadá con $8.4 \%$ y Oceanía con $5.2 \%{ }^{41}$.

\footnotetext{
${ }^{40}$ Seis bancos tenían capital superior a los 100 millones de Marcos para 1910, el Deutsche Bank con 200 millones, el Dresdener con 180 millones, el Diskontogesellschaft con 170 millones, el Darmstädter con 154 millones, el Schaffhausen'schen Bank con 145 millones, y el Berliner Handelsgesellschaft con 110 millones. Kindleberger (1984) p.129

${ }^{41}$ Feis (1930) p. 11-75 


\begin{tabular}{|l|c|}
\hline \multicolumn{2}{|c|}{$\begin{array}{c}\text { Tabla 2.4 } \\
\text { Inversión Extranjera Alemana x Destino } \\
\text { En Miles de Millones de Marcos }\end{array}$} \\
\hline \multicolumn{1}{|c|}{ Territorio } & Valor \\
\hline Austria-Hungría & 3,0 \\
\hline Rusia & 1,8 \\
\hline Países Balcánicos & 1,7 \\
\hline Turquía (Europa y Asia) & 1,8 \\
\hline Francia y Gran Bretaña & 1,3 \\
\hline España y Portugal & 1,7 \\
\hline Resto de Europa & 1,2 \\
\hline África (Incluidas colonias alemanas) & 2,0 \\
\hline Asia (Incluidas colonias alemanas) & 1,0 \\
\hline Estados Unidos y Canadá & 3,7 \\
\hline Latinoamérica & 3,8 \\
\hline Otras Zonas & $\mathbf{2 3 , 5}$ \\
\hline Total & \\
\hline
\end{tabular}

Fuente: Feis 1930, p. 74

Si se sustentara el imperialismo como un elemento de poder y capacidad militar y no sobre la movilidad de los factores de producción y su optimización, se podrían analizar las cifras militares, donde el mayor crecimiento del aparato militar estuvo en países como Alemania. Aunque es importante mencionar que las potencias principales de la Europa del siglo XIX estaban interesadas en ampliar su capacidad militar, en algunos casos obsoleta, a través de una nueva y eficiente máquina de guerra; era necesario contar con un alto nivel de recursos económicos, por la misma característica de innovación que se presentaba en la industria bélica.

En ese momento no hubo necesidad de contar con una economía dinámica y pujante que le permitiera al Estado obtener recursos frescos a través de una política de impuestos agresiva, sino 
tener la capacidad diplomática de involucrar a los grandes banqueros de países como Inglaterra, Alemania y Francia en la financiación o asesoría para la consecución de capital a través de diversos vehículos o préstamos y, de esta forma, buscar la supervivencia de su estructura, que ya mostraba señales de debilidad. El Imperio Otomano, el Imperio Austro Húngaro y el Imperio Ruso son ejemplos de esto; aclarando que sustentar con deuda un gasto sin retorno e improductivo, como lo es el gasto militar, conduciría a una profundización del déficit fiscal y a un deterioro económico que se trasladaría a las generaciones futuras.

Es importante revisar el avance de algunas variables militares para sustentar el párrafo anterior. Alemania aumentaba su capacidad naval rápidamente, gracias a su capacidad económica. El crecimiento de 1880 a 1914 fue superior al 1.382\%, pasando de ser la antepenúltima potencia en capacidad naval a ser la segunda al iniciarse la Primera Guerra Mundial; y teniendo una relación con Gran Bretaña para 1880 de 0.13 toneladas por cada 1 que tenían los británicos, y para 1914 esta relación pasaría a 0.60 toneladas (Ver Tabla 2.5). El caso de Japón también muestra una importante consolidación naval en comparación a lo que sucedió con otros países. Siendo la fuerza más débil para 1880, crecería en un 4.566\% hasta 1914, y ya para 1905 había derrotado al gran Imperio Ruso que, como consecuencia de su debilidad económica, no podía mantener el ritmo de gasto militar que tenían las demás potencias, lo que da como resultado una tasa de crecimiento más lenta, de aproximadamente el $240 \%$, durante el periodo soportado en gran proporción por sus socios interesados en mantener una capacidad militar que les favoreciera en sus procesos de alianza.

\begin{tabular}{|l|r|r|r|r|r|}
\hline \multicolumn{7}{|c|}{$\begin{array}{c}\text { Tabla 2.5 } \\
\text { Tonelaje en Buques de Guerra de las Potencias, 1880-1914 } \\
\text { (En miles) }\end{array}$} \\
\hline \multicolumn{1}{|c|}{ País } & $\mathbf{1 8 8 0}$ & $\mathbf{1 8 9 0}$ & \multicolumn{1}{|c|}{$\mathbf{1 9 0 0}$} & \multicolumn{1}{c|}{$\mathbf{1 9 1 0}$} & $\mathbf{1 9 1 4}$ \\
\hline Gran Bretaña & 650 & 679 & 1.065 & 2.174 & 2.174 \\
\hline Francia & 271 & 319 & 499 & 725 & 900 \\
\hline Rusia & 200 & 180 & 383 & 401 & 679 \\
\hline $\begin{array}{l}\text { Estados } \\
\text { Unidos }\end{array}$ & 169 & 240 & 333 & 824 & 985 \\
\hline Italia & 100 & 242 & 245 & 327 & 498 \\
\hline Alemania & 88 & 190 & 285 & 964 & 1.305 \\
\hline $\begin{array}{l}\text { Austria- } \\
\text { Hungría }\end{array}$ & 60 & 66 & 87 & 210 & 372 \\
\hline Japón & 15 & 41 & 187 & 496 & 700 \\
\hline Fuente: Kennedy (1987) p. $\mathbf{3 2 9}$ & & & & \\
\hline
\end{tabular}


Esta era la situación de Rusia, la cual se logró mantener hasta entrado el siglo XX, gracias al apoyo que recibió de Alemania, Francia y Gran Bretaña, en diferentes momentos. Rusia era un territorio imperial que se sostenía por la capacidad económica de otros imperios y no por sí mismo; no tenía la capacidad de acumular capital para mantenerse en esa carrera imperialista, aunque quisiera seguir aparentando una fortaleza que solo se percibía efectiva por su contundente personal militar y las bondades de la herencia y la tradición imperial. Ya Pedro el Grande lo había mencionado: el poder militar en el exterior dependía del desarrollo tanto político como económico en el propio país; un país en donde la revolución industrial llegó tarde y en cabeza de inversionistas extranjeros y no a partir de procesos independientes de emprendimiento ruso.

La gran potencia naval del siglo XIX, Inglaterra, solo creció en un 234\% durante el periodo, pero continuaba manteniendo una capacidad inigualable, que solo sería superada después de finalizar la Gran Guerra por los Estados Unidos que, con un crecimiento del 483\%, para 1914 sería la tercera potencia naval, superando a Francia, que contaba con una mayor tradición naviera, pero con la diferencia que su posibilidad de acumulación generada por su importante avance económico, superior al de varios países europeos, sería el artífice de esa consolidación.

Los países que obtuvieron un mayor crecimiento en su capacidad naval, elemento relevante para la consolidación militar y la evolución de las futuras luchas armadas, fueron los que contaron con un mayor crecimiento económico durante los últimos años del siglo XIX y principios del siglo XX: Alemania, Estados Unidos y Japón. Algo importante que aclara que la vanidad política y hegemónica de algunos países se lograba gracias a los recursos con que contaba, soportándose sobre una variable muy valiosa, la capacidad de gestión de sus gobiernos para administrarlos.

El gasto militar siempre se ha reducido en épocas de paz y se ha incrementado durante periodos bélicos. El avance económico permitió que con la presencia del desequilibrio político que se gestaba con la pérdida del liderazgo británico se iniciara una carrera armamentista y un incremento en el gasto militar considerable, la estabilidad y la confianza entre los países se había empezado a deteriorar desde la misma Guerra de Crimea, que permitiera contrarrestar cualquier agresión y en su defecto la necesidad de iniciar la organización de alianzas soportado ya no sobre el casus belli, sino asegurándose que cada aliado se movilizaría en cuanto lo hiciera un adversario y no solamente garantizando el apoyo después de iniciada una guerra ${ }^{42}$.

En 1891 el gasto en defensa, como porcentaje del gasto público total, era del $24.9 \%$ para Francia, $26.7 \%$ para Gran Bretaña y $26.3 \%$ para Alemania. Ya para 1913, el gasto francés y británico se habían incrementado al $28.8 \%$ y $29.9 \%$ respectivamente, y el alemán se mantenía casi que estable en $26.6 \%$, con la diferencia de contar con una economía más fuerte y un producto bruto y un gasto público en ascenso. El promedio del gasto de defensa, como porcentaje del producto nacional neto entre 1870 y 1913, aumentó al 3.1\% para Gran Bretaña y Austria, 3.2\% para Alemania, 3.3\% para

\footnotetext{
${ }^{42}$ Kissinger (1995) p. 198
} 
Italia y $4 \%$ para Francia. Estados Unidos gastó menos que el $1 \%$ de su ingreso nacional neto entre 1870 y $1913^{43}$

\begin{tabular}{|c|c|c|c|c|c|}
\hline \multicolumn{6}{|c|}{$\begin{array}{c}\text { Tabla } 2.6 \\
\text { Personal militar y naval, 1880-1914 } \\
\text { (En miles) }\end{array}$} \\
\hline País & 1880 & 1890 & 1900 & 1910 & 1914 \\
\hline Rusia & 791 & 677 & 1.162 & 1.285 & 1.352 \\
\hline Francia & 543 & 542 & 715 & 769 & 910 \\
\hline Alemania & 426 & 504 & 524 & 694 & 891 \\
\hline Gran Bretaña & 367 & 420 & 624 & 571 & 532 \\
\hline Austria-Hungría & 246 & 346 & 385 & 425 & 444 \\
\hline Italia & 216 & 284 & 255 & 322 & 345 \\
\hline Japón & 71 & 84 & 234 & 271 & 306 \\
\hline Estados Unidos & 34 & 39 & 96 & 127 & 164 \\
\hline
\end{tabular}

que consumía, a su vez, importantes recursos y que finalmente no se lograría optimizar si no se contaba con los medios logísticos adecuados. El tamaño de la población rusa y, por consiguiente, el tamaño de su ejército era aterradora en el papel, pero era menos impresionante por la escasez de líneas férreas para su despliegue y por la incompetencia administrativa ${ }^{44}$.

En 1913 Rusia contaba con una población de 175 millones de habitantes, seguido de Estados Unidos con 97.3 millones, Alemania con 66.9 millones, Gran Bretaña con 45.6 millones y Francia con 39.7 millones $^{45}$, donde la población involucrada en actividades militares de Francia superaba el $2.99 \%$, Alemania $1.33 \%$, Gran Bretaña $1.16 \%$, Rusia $0.77 \%$ y Estados Unidos $0.17 \%$. Esto nos permite concluir que Estados Unidos no estaba en una carrera militar como los países europeos y que las grandes potencias centrales contaban con la capacidad de avanzar en un fortalecimiento de sus filas militares; algo diferente sucedía con Rusia, que aunque tenía una fuerza militar consolidada desde tiempo atrás, no tenía los recursos para ampliarla y estar a la par en los porcentajes de las potencias europeas. Los ejércitos europeos sufrieron diversas dificultades, hasta la misma Alemania, donde el número de soldados Ilamados a filas se vio limitado por restricciones presupuestarias y por la resistencia de un Reichstag de tendencias cada vez más de izquierda, así como por la reticencia del propio ejército a reclutar de entre la creciente y políticamente poco fiable población urbana ${ }^{46}$.

\footnotetext{
${ }^{43}$ Ferguson (2001) p.44-47

${ }^{44}$ Howard (2002) p.36

${ }^{45}$ Kennedy (1987) p. 322

${ }^{46}$ Howard (2002) p. 36
} 
Sin embargo, la población alemana se había elevado de 49 millones en 1890 a 66.9 millones en 1913 y solo era superada por Rusia en Europa; pero como los alemanes disfrutaban de niveles más altos de educación, previsión social y renta per cápita que los rusos, la nación era fuerte tanto por la cantidad como por la calidad de su población ${ }^{47}$. Esto no solo se vivió en los aspectos previos a la guerra, sino que los modelos de educación alemana en diferentes niveles y apartados de las ciencias sociales y las humanidades, propias de la educación británica, permitirían el fortalecimiento de diferentes grupos sociales y poblacionales para atender las necesidades de la industria. Es decir, todos los frentes de la jerarquía empresarial podían ser atendidos gracias al esquema educativo.

El avance económico por sí solo podría establecer a Alemania como una potencia mundial, comparada con Inglaterra y Estados Unidos, en 1913, ya los superaba en diversos sectores económicos (Ver Tabla 2.7), con un mercado interno dinámico y en desarrollo, así como una participación en el comercio internacional con países industrializados mayor que el de cualquier país, profundizando más la decadencia del comercio británico, el cual se especializaba en mercados menos competitivos y en donde sus productos manufacturados no demandaban el mismo valor agregado que se solicitaba en los mercados industrializados.

El comercio exterior ayuda a explicar el vigor de la economía; pero si esta fuera toda la historia, de seguro la economía alemana habría fluctuado tan ampliamente como la británica. Es claro que esta economía, como la norteamericana, estaba impulsada por poderosas fuerzas de transformación interna, derivadas del mismo hecho de que, al contrario de Gran Bretaña, todavía tenía un gran sector agrícola y una potencialidad considerable para la aplicación de nueva tecnología agrícola e industrial. Una vez que empiezan, las economías atrasadas pueden crecer más de prisa que las precursoras $^{48}$.

\begin{tabular}{|c|c|c|c|c|}
\hline \multicolumn{5}{|c|}{$\begin{array}{c}\text { Tabla } 2.7 \\
\begin{array}{c}\text { Exportaciones de Manufacturas de los Países centrales, } 1913 \\
\text { (millones de dólares a precios constantes) }\end{array}\end{array}$} \\
\hline A & $\begin{array}{c}\text { De } \\
\text { Alemania }\end{array}$ & $\begin{array}{l}\text { De } \\
\text { Estados } \\
\text { Unidos }\end{array}$ & $\begin{array}{c}\text { De } \\
\text { Francia }\end{array}$ & $\begin{array}{l}\text { Del } \\
\text { Reino } \\
\text { Unido }\end{array}$ \\
\hline Países Industriales & 925 & 535 & 502 & 624 \\
\hline $\begin{array}{l}\text { Países Semi } \\
\text { industrializados }\end{array}$ & 218 & 137 & 83 & 810 \\
\hline Resto del mundo & 583 & 174 & 202 & 526 \\
\hline Total & 1726 & 846 & 787 & 1960 \\
\hline
\end{tabular}

\footnotetext{
${ }^{47}$ Kennedy (1987) p. 339

${ }^{48}$ Lewis (1978) p. 45
} 
En 1913, la participación en la exportación global de manufacturas estaba concentrada en cuatro países: Reino Unido con un 30.17\%, Alemania 26.57\%, Estados Unidos $13.02 \%$ y Francia $12.11 \%$. Las naciones que en ese momento buscaban consolidar su hegemonía económica y política, además de contar con una estructura económica e industrial que les respaldara sus intenciones, tenían más del $80 \%$ del comercio global de manufacturas. Factor relevante para entender cómo países que participaron en la Conferencia de Berlín con una intención política de avanzar territorialmente sobre África, como Austria-Hungría, Rusia, Suecia, Dinamarca, entre otros, no tuvieron la capacidad de lograrlo, simplemente porque su infraestructura económica, su posibilidad de acumular capital, innovar tecnológicamente, tener objetivos de inversión extranjera o transformar el capital a capital financiero no fue suficiente o insignificante en comparación con Inglaterra, Estados Unidos, Alemania y Francia. Aunque la ineficiencia económica de Rusia buscaba reducir con una lógica imperial territorialista avanzar hacia Oriente, hasta donde las posibilidades de su fuerza se lo permitieran, había la posibilidad de obtener recursos naturales que le redujeran su desequilibrio frente a las demás potencias, pues en Europa su visión imperialista era difícil de lograr y tenía todo que perder en una guerra con Alemania ${ }^{49}$.

Los países del centro no solamente se vincularon con diversos territorios en América, África y Asia, sino que fueron relevantes en el ajuste y financiación de gobiernos que se encontraban en dificultades fiscales o requerían de importantes recursos para mantener sus esquemas imperiales, como el caso de Rusia y Austria-Hungría; consolidarse como naciones, como el caso de Italia; solventar sus faltantes financieros debido a la pérdida de sus colonias, como el caso de Portugal, y una debilidad territorial cada vez mas latente del Imperio Otomano. Es decir, los Estados que no habían logrado engranar una economía dinámica interna y externamente, estaban supeditados a dejar sus aspiraciones territoriales, concentrarse en sus territorios actuales y lograr mantener adecuadamente el equilibrio de su estructura política y económica.

Estos países, que no habían contado con una interacción comercial sustentable en el tiempo, como los británicos durante el siglo XIX, los mismos holandeses durante el siglo XVIII, o aquellos países que lo estaban logrando como Alemania y los Estados Unidos en los últimos años del siglo XIX, no lograron los procesos de acumulación que el comercio permitía y transformarlos en capital financiero o capital para inversión; es decir, la acumulación y el posterior corretaje de materias primas y bienes básicos conduciría a que los préstamos extranjeros se convirtieran en una consecuencia natural ${ }^{50}$. En otras palabras, el control del capital por parte del capital, es decir, del capital industrial por el capital financiero, representaba el más alto y prístino estado del desarrollo capitalista ${ }^{51}$, pero en especial en el último cuarto del siglo XIX, los procesos industriales que se habían desarrollado estaban controlados por los grandes bancos, haute finance, que funcionó como el vínculo principal entre la organización política y económica del mundo ${ }^{52}$.

\footnotetext{
${ }^{49}$ Kissinger (1995) p. 172

${ }^{50}$ Kindleberger (1984) p.38

${ }^{51}$ Gilpin (1987) p. 50

52 Polanyi (1957) p. 10
} 


\section{EL AFÁN DE HEGEMONÍA: GUERRA, ALIANZAS Y ECONOMÍA}

Cuando se saca el genuino sentir nacionalista de sus cauces naturales y se lo utiliza para invadir y anexionarse el territorio cercano o distante de pueblos que no lo desean y que resultan inasimilables, nos encontramos con una degeneración del autentico nacionalismo, que señala la transición del nacionalismo a un colonialismo espúreo, por una parte, y al imperialismo, por la otra.

Hobson

Con la entrada en vigencia del Congreso de Berlín, se abre una puerta a que los países que contaran con la capacidad de aventurarse en proyectos coloniales de ultramar avanzaran en el territorio africano y lograran consolidar un territorio (protectorado o colonia) que los abasteciera de materias primas. En este momento, los países que contaban con una tradición colonial tenían una ventaja sobre aquellos países que iniciaban este proceso, pero gracias a su estructura económica y su acumulación de capital podrían entrar en una competencia por los nuevos territorios donde, como se presentó en la sección anterior, Alemania, al interior de Europa, contaría con esa nueva faceta y dejaría relegados a Austria-Hungría, Rusia, Portugal y España, con una tradición imperial de siglos.

En ese momento se inicia una carrera imperial que ya no era exclusiva y que conduciría a buscar los mayores beneficios en diferentes lugares del mundo, donde la capacidad de imposición o negociación los determinarían, a partir de los intereses que tenían en cada uno de los territorios que lógicamente se definían con diferentes estrategias económicas y políticas, fundamentadas en una estrategia general: Consolidarse en la hegemonía global.

No era lo mismo la estrategia para las colonias británicas, o para los nuevos países con herencia anglosajona como Estados Unidos, Canadá o Australia, o territorios en donde su único vínculo era la posibilidad de desarrollar importantes negocios que se sustentaban en la exportación de capital, pero nunca en la imposición política, pues se desprendían costos económicos y políticos muy altos, como es el caso de Latinoamérica. Esto conduce al avance de varios países, y al inicio de la decadencia del Imperio Británico, generando una competencia de varios imperios al mismo tiempo, cada uno poniendo en práctica su propia política imperialista de expansión industrial y territorial, convirtiéndose inevitablemente en enemigos ${ }^{53}$.

Las intenciones de fortalecerse condujeron al cambio de estrategias de política exterior con diferentes territorios de ultramar; la posición ya no era de relación sino de imposición y, en muchos casos, las potencias cambiaron el estatus de esos territorios y el manejo de ellos. Inglaterra ya no gestionaba las relaciones con territorios africanos bajo el Ministerio de Relaciones Exteriores sino bajo el Ministerio de Colonias. Y aunque siguiera siendo la potencia más grande del mundo y la orgullosa dueña del mayor imperio que el mundo hubiera visto, era más vulnerable de lo que nunca lo había sido en toda su historia ${ }^{54}$.

\footnotetext{
${ }^{53}$ Hobson (1902) p. 33

${ }^{54}$ Howard (2002) p. 12
} 
Teniendo presente que el factor económico es la pieza fundamental para el avance como potencia, aunque en ocasiones se trata de diferenciar al poder como parte del intercambio político y al dinero como parte del intercambio económico ${ }^{55}$, ¿cuál fue la necesidad de conducir al imperialismo moderno, que se sustentaba sobre la competencia económica, a retomar la rivalidad territorial y hegemónica?: la vanidad política y la imprecisión diplomática, las cuales se sustentaron en la gestión de los gobiernos y la combinación del éxito económico con que algunos contaban para consolidar una posición relevante en el sistema internacional y en tener la capacidad adecuada para responder a la guerra que se avecinaba. Varias naciones fueron a la guerra con una simple herencia, una capacidad militar con altos niveles de endeudamiento y una dinámica económica inferior a países como Alemania e Inglaterra, Francia en menor proporción y, finalmente, los Estados Unidos a su ingreso en Abril de 1917. Ese desafío alemán y estadounidense al poder mundial británico se reforzó recíprocamente, comprometieron la capacidad británica para gobernar el sistema interestatal y, finalmente, desembocaron en una nueva lucha por la supremacía mundial de una violencia y de una crueldad sin precedentes ${ }^{56}$.

Aunque la interdependencia económica no es el único ni el más importante conjunto de relaciones que existen entre los Estados y las relaciones políticas y estratégicas entre los agentes políticos son de igual o mayor significado, y no pueden reducirse a mera consideraciones económicas, como lo menciona Gilpin ${ }^{57}$; es importante establecer qué elemento político conecta ese engranaje, para que los países interesados en dominar el sistema internacional deban acudir a acciones políticas impositivas o militares para lograr su objetivo y terminar en lo sucedido en la Gran Guerra.

El elemento político se puede sustentar en la diplomacia, en los procesos de alianza que se concretaron durante este periodo y en la desconfianza política. Esto determina por qué Alemania generó una capacidad militar tan potente en tan corto tiempo y así evitar cualquier acción en su contra; teniendo presente que los territorios de la actual Alemania habían sido durante siglos el lugar de las confrontaciones europeas y en donde nunca se había participado de la victoria. En ese momento, con una Alemania unificada y fuerte económicamente, el pensamiento de los estrategas alemanes, en combatir simultáneamente a una combinación de todos los vecinos de Alemania ${ }^{58}$, era cada vez más una realidad. Y esta era una de las razones para que los países empezaran la búsqueda de alianzas para contrarrestar en cualquier momento un avance alemán, el cual entre más aumentaba su propia fuerza más favorecían la formación de coaliciones compensadoras ${ }^{59}$.

Las imprecisiones y la interpretación inadecuada de los procesos diplomáticos en Europa condujeron a afianzar las alianzas; peor aún cuando los intereses nacionales empezaron a creerse afectados

\footnotetext{
${ }^{55}$ Baldwin (1971) p. 585

${ }^{56}$ Arrighi (1999) p. 78

${ }^{57}$ Gilpin (1987) p. 63

${ }^{58}$ Kissinger (1995) p. 165

${ }^{59}$ Ibid. p. 167
}

IMPERIOS Y COLONIALISMO, 1870-1914 ¿UNA ERA DE GLOBALIZACIÓN, GEOPOLÍTICA O NACIONALISMO ECONÓMICO? 
por las decisiones políticas de otros, y en esa desesperación se desarrollarían alianzas, simplemente para evitar cualquier ataque de las demás, sin importar qué afinidad política, de objetivos o de intereses tuvieran.

La alianza entre Alemania y Austria-Hungría se había mantenido después de la salida de Rusia de la Alianza de los Tres Emperadores, establecida en 1873, para constituirse en la Triple Alianza con la entrada de Italia en 1882, siendo la primera de las alianzas previas a la Gran Guerra. Así mismo, los franceses al ver el avance y fortalecimiento de Alemania y convirtiéndose en un enemigo común para Rusia y Francia, consideran oportuno iniciar una colaboración diplomática con la Entente Cordiale, en 1891, que se sustentaba también como reacción a los acuerdos coloniales que Gran Bretaña y Alemania habían firmado sobre algunas posesiones en África.

Rusia veía a Inglaterra como su gran enemigo colonial, pero Inglaterra se mantenía en su aislamiento espléndido, siendo cortejado por las dos alianzas, y solo sería hasta entrado el año de 1908 en donde se uniría a Francia y Rusia en la Triple Entente. Algo que mostraba la preocupación de Inglaterra por el avance en Europa de Alemania, distanciándose de una tradición diplomática que lo había mantenido alejado de alianzas que no tuvieran una conexión completa con sus objetivos e intereses, y más con países con los cuales había tenido importantes diferencias en el pasado. Esa tradición británica había encontrado una preocupación tan grande con Alemania y su avance en diferentes esferas, que su interés nacional se sintonizaba con el de Francia y Rusia. En este punto estaban definidas las estructuras que se enfrentarían en la Primera Guerra mundial.

Esa conjugación diplomática se soportaba sobre las bondades con que contaba cada uno de los países, en distinguir los recursos de poder de otras $\operatorname{cosas}^{60}$ y determinar que, aunque los aspectos políticos se estaban saliendo de las manos, no era claro cuáles eran los recursos para involucrarse en una guerra; posiblemente el que contaba con mayor capacidad de afrontar la situación en todo sentido era Alemania. El marxismo no puede explicar el hecho de que los tres grandes imperios rivales -Gran Bretaña, Francia y Rusia- estuvieran en el mismo bando durante la contienda subsiguiente y que lucharan contra una Alemania que tenía pocos intereses de política exterior fuera de Europa ${ }^{61}$. La única forma de reducir a la próxima potencia mundial era aprovechar la vanidad e imprecisión diplomática de sus dirigentes, porque en el terreno económico era cada vez más complejo poder detener la maquinaria alemana.

Los dirigentes políticos podrían estar interesados en hacer la guerra a sus contrincantes territoriales y acudir a la financiación de empresarios y banqueros, pero realmente estos eran los vehículos para financiar la maquinaria de la guerra, esto era un proceso impositivo por parte de los dirigentes políticos sobre los dueños del capital, o más bien un proceso en donde el beneficio económico que recibe el capital es más importante que la ética de involucrarlo en una guerra. Durante una

\footnotetext{
${ }^{60}$ Baldwin (1979) p. 164

${ }^{61}$ Gilpin (1987) p. 65
} 
guerra de estas dimensiones la única actividad rentable es su financiación, que dependiendo de la voracidad y el impacto territorial que tenga, las demás actividades en donde se puede beneficiar el capital están detenidas o no pueden activarse permanentemente durante el conflicto.

Las actividades en los mercados de valores sufrieron trastornos y posiblemente fueron influenciados por los precios que tenían los activos de los países involucrados en la guerra. Muestra de esto, y afianzando la conclusión de la importancia de la acumulación de capital y el avance económico con que cuenta cada nación, es revisar el impacto que tuvieron los bonos gubernamentales en las situaciones previas al inicio de la guerra, que se negociaban en Londres o Paris; el impacto de aquellos países que aunque contando con una relativa importancia militar, pero una debilidad en su estructura económica y tecnológica, podría sufrir el incremento en la tasa de sus títulos, un aumento en el riesgo y en la perspectiva de los inversionistas sobre ese país, y la posibilidad de no contar con la capacidad para sostenerse en una guerra, debido a que al acudir a los mercados financieros por nuevos recursos, los inversionistas castigarían su debilidad económica pre y posguerra.

Durante la crisis, previa a la gran guerra, iniciada el 28 de junio de 1914 con el asesinato del heredero al trono de los Habsburgo en Sarajevo y las posteriores declaraciones de guerra durante todo el mes de julio, se presenta un impacto en la tasas de los títulos de los gobiernos involucrados, y se manifiesta sobre la capacidad económica que tenían para dar respuesta a la confrontación. Los bonos del Gobierno Ruso tuvieron un incremento de 52 puntos básicos, y los del Imperio Austro Húngaro de 42 puntos básicos; claramente los dos países con las mayores dificultades de absorber los impactos de la guerra. Los bonos ingleses tuvieron un incremento de 22 puntos básicos, teniendo presente que el dinamismo de su economía se venía perdiendo desde tiempo atrás, y podría ser el mayor perjudicado en un evento bélico de estas dimensiones por la gran cantidad de territorios que posiblemente debía proteger; y finalmente, el gobierno francés tuvo un incremento de 5 puntos básicos durante el periodo ${ }^{62}$.

Así mismo, al Ilamado de la guerra, los países acudieron a su capital para poder iniciar y sostener el enfrentamiento; para ese momento los países iniciaban la liquidación de sus portafolios de inversión, Francia e Inglaterra solicitan a Estados Unidos el sostener sus divisas con operaciones interbancarias y a la financiación externa a través de entidades bancarias estadounidenses o por importantes procesos de emisión de bonos; la guerra, declaraba el antiguo filosofo griego Heráclito, es el padre de todas las cosas. Es acertadamente el padre del mercado de bonos ${ }^{63}$.

El elemento político nuevamente llegaba a su necesaria conexión con el factor económico revisando elementos externos a su economía interna. El afán por la hegemonía causada por los asuntos políticos se convirtió en guerra, y su sostenimiento fue claramente económico, donde el país que

\footnotetext{
${ }^{62}$ Ferguson (2001) p. 276

${ }^{63}$ Ferguson (2008) p. 70
} 
contara con mayores reservas de sus recursos de poder sería el gran vencedor. El desenlace de la guerra no forma parte de nuestro análisis, pero claramente el desacierto político condujo al deterioro económico de una época boyante para las economías de centro y para la economía mundial en general; un avance de estas dimensiones, como el vivido durante los años previos a la Primera Guerra Mundial, no se volvería a lograr.

\section{CONCLUSIONES}

Los imperios y los procesos coloniales durante la era de 1870 a 1914, se gestaron por el agotamiento de dos equilibrios. El equilibrio político del poder que se había logrado en el Congreso de Viena, en 1815, con varias situaciones desequilibrantes, pero no en la dimensión a la que los pueblos europeos estaban acostumbrados. Y el rompimiento del equilibrio económico que se había generado por la dominación absoluta del Imperio Británico desde casi principios del siglo XIX.

El avance económico de algunos países que no habían iniciado a profundidad un proceso industrial debido a su inestabilidad territorial y, por ende, su atraso industrial, serían los nuevos artífices del sistema económico internacional, en donde esa capacidad económica, sustentada sobre procesos de innovación y progreso tecnológico, así como de la optimización de los factores de producción, serían los que iniciarían el aprovechamiento de los recursos y mercados que habían sido exclusivos del Reino Unido.

Esto contrastaría con la deficiencia del mercado interno británico, el cual vio que la mejor posibilidad para mantener su estructura hegemónica era la optimización del capital y para esto requería, no solamente mantener su mercado externo, sino fortalecer sus procesos de inversión, dejando en ocasiones al mercado interno sin los recursos necesarios para reconvertirse industrialmente. Sin embargo, en ocasiones fue más sencillo trasladar esos recursos a nuevos mercados que se vincularan a los intereses económicos y evitar los procesos de reconversión que implicaban dificultades y trastornos en los procesos productivos. Estados Unidos y Alemania lograron avanzar en ese proceso, pero nunca dejaron de lado su mercado interno, el cual gozaba de inmensas oportunidades, así como la optimización de los factores de producción y la especialización industrial que permitía el progreso tecnológico, de la mano de sistemas adecuados de educación.

La competencia económica, lejos de la rivalidad territorial que se había vivido en Europa durante todos los años de su consolidación política, era el artífice de la interacción más importante del sistema internacional. Pero en el momento en que fue necesario avanzar con más fuerza en esa competencia económica, se acude al acuerdo imperialista de Berlín, contrarrestando cualquier enfrentamiento territorial o declaración de guerra. Se buscaba salvaguardar la competencia económica antes que el enfrentamiento, pero bajo una concepción antigua donde primaba la jerarquía de las relaciones internacionales: desde el intercambio hasta la dominación. 
El afán de posicionamiento en los mercados internacionales podría ser el inicio para que el sistema capitalista no estuviera capacitado para absorber la producción global y sostener el ciclo económico ascendente que, a pesar de algunas desaceleraciones y crisis puntales, era positivo, pero fácilmente vulnerable. Era la estabilidad hegemónica de Keohane ${ }^{64}$, que estaba llegando a su fin, prediciendo una decadencia del poder económico británico y la necesidad del reacomodamiento de fuerzas y los recursos de poder.

Conectando esto a la desconfianza política entre las potencias, que no era diferente a épocas anteriores, la vanidad del poder, la errada interpretación diplomática, el exceso capitalista y la intención de buscar la hegemonía global, por encima de cualquier cosa, logra reactivar las rivalidades, el accionar de principios del siglo XIX y la herencia de guerra con que Europa había convivido por más de 2000 años; solo con la diferencia que muchos de ellos contaban con una estructura de acumulación de capital autónoma y suficiente para fortalecer sus recursos de poder y establecer el Imperio del siglo XX.

\section{BIBLIOGRAFÍA}

- $\quad$ ARRIGHI, G. (1999) El largo Siglo XX. Dinero y Poder en los orígenes de nuestra época. Madrid, edición en español. Ediciones Akal.

- $\quad$ BALDWIN, D. (1979) «Power and money» The Journal of politics, Vol. 33, No. 3, p. 78-614.

- $\quad$ BALDWIN, D. (1979) «Power analysis and world politics: New trends versus old tendencies» World Politics, Vol. 31, No. 2, p. 161-194.

- $\quad$ FERGUSON, N. (2001) The Cash nexus: Money and power in the modern world. New York: Basic Books.

- $\quad$ FERGUSON, N. (2005) «Sinking globalization» Foreign Affairs, Vol. 84, No. 2, p.64-77.

- $\quad$ FERGUSON, N. (2006) «Empires with expiration dates» Foreign Policy, No. 156, p. 46-52.

- $\quad$ FERGUSON, N. (2008) The ascent of money. A financial history of the world. New York: Penguin Books.

- $\quad$ FEIS, H. (1930) Europe: The world's banker, 1870-1914. New Haven: Yale University Press.

\footnotetext{
${ }^{64}$ Keohane (1980) p.132
}

IMPERIOS Y COLONIALISMO, 1870-1914 ¿UNA ERA DE GLOBALIZACIÓN, GEOPOLÍTICA O NACIONALISMO ECONÓMICO? 
- FIELDHOUSE, D. K. (1961) «Imperialism: An historiographical revision». The Economic History Review, Vol. 14, No. 2, pp. 187-209.

- $\quad$ FOUCAULT, M. (2004) Seguridad, territorio y población. Buenos Aires, Edición en español por Fondo de Cultura económica 2006.

- GILPIN, R. (1987) La economía política de la relaciones internacionales. Buenos Aires, Edición en español por Grupo Editor Latinoamericano.

- $\quad$ HARDT, M.; Negri, A. (2000) Empire. Cambridge: Harvard University Press.

- HEGEL, G.F. (1975) Filosofía del Derecho. México, D.F., Edición en español por Universidad Nacional Autónoma de México.

- $\quad$ HOBSON, J.A. (1902) Imperialism: A study. London: George Allen \& Unwin.

- $\quad$ HOWARD, M. (2002) The first world war. Oxford: Oxford University Press.

- $\quad$ KANT, Emanuel (1795) Sobre la paz perpetua. Madrid, edición en español por Alianza Editorial, Primera Impresión 2002.

- $\quad$ KENNEDY, P. (1987) Auge y caída de las grandes potencias. Barcelona, edición en español por Plaza \& Janes editores.

- $\quad$ KEOHANE, R. (1980) «The theory of hegemonic stability and change of international economic regimes. In: Change in international system. Edited by O. Holsti et al., p. 131-162. Boulder: Westview.

- $\quad$ KINDLEBERGER, C. (1970) Power and Money. The economics of international politics and the politics of international economics. New York: Basic books, Inc.

- $\quad$ KINDLEBERGER, C. (1984) A financial history of Western Europe. New York: Oxford University Press.

- $\quad$ KINDLEBERGER, C. (1989) Manias, panics and crashes. New York: Basic books, Inc.

- $\quad$ KISSINGER, H. (1995) La Diplomacia. México, D.F., Edición en español por Fondo de Cultura Económica.

- $\quad$ KOEBNER, R. (1949) «The Concept of Economic Imperialism». The Economic History Review, Vol. 2, No. 1, pp. 1-29. 
- $\quad$ KUZNETS, S. (1966) Modern economic growth: rate, structure and spread. New Haven: Yale University Press.

- $\quad$ LEWIS, W. A. (1978) Crecimiento y Fluctuaciones 1870-1913. México, D.F., Edición en español por Fondo de Cultura Económica, 1983.

- $\quad$ LINDBLOM, C. (1977) Politics and markets: The world's political economic systems. New York: Basic Books.

- $\quad$ LOCKE, J. (1690). Segundo Tratado sobre el Gobierno Civil. Madrid, Edición en español por Alianza Editorial, Cuarta Reimpresión 2006.

- $\quad$ LUXEMBURGO, R. (1968) The Accumulation of capital. Nueva York: Monthly Review Press.

- $\quad$ MAIZELS, A. (1963) Industrial growth and world trade. Cambridge: Cambridge University Press.

- MONTESQUIEU (1748) El Espíritu de las Leyes. Barcelona, Edición en español por Edicomunicación S.A., 2003.

- $\quad$ POLANYI, K. (1957) The great transformation: The political and economic origins of our time. Boston: Beacon Press.

- POLLARD, S. (1985) «Capital Exports, 1870-1914: Harmful or Beneficial?» The Economic History Review, Vol. 38, No. 4, pp. 489-514.

- $\quad$ VINER, J. (1958) The long view and the short: Studies in economic theory and policy. New York: Free Press.

- $\quad$ YATES, P. (1959) Forty Years of foreign trade. London: George Allen \& Unwin. 